\title{
FAKTOR LINGKUNGAN DAN PERILAKU YANG BERPENGARUH TERHADAP KEJADIAN FILARIASIS
}

\author{
Yusuf Lensa Hamdan ${ }^{1}$, Suharyo Hadisaputro ${ }^{1}$, Ari Suwondo ${ }^{1}$, Muchlis AU Sofro ${ }^{2}$, Sakundarno Adi ${ }^{1}$ \\ ${ }^{1}$ Program Studi Magister Epidemiologi, Sekolah Pascasarjana Universitas Diponegoro \\ ${ }^{2}$ Bagian Ilmu Penyakit Dalam RSUP dr. Kariadi/Fakultas Kedokteran Universitas Diponegoro \\ yusuflensahamdan@gmail.com
}

\begin{abstract}
ABSTRAK
Filariasis merupakan penyakit yang masih menjadi masalah kesehatan di Indonesia. Kecamatan Pekalongan Selatan merupakan salah satu daerah endemis filariasis yang terdapat 71 kasus filariasis yang mungkinkan oleh berbagai faktor lingkungan yang banyak terdapat rawa dan kolam dan digenangi air serta ditumbuhi oleh tanaman air. Faktor lain selain dari faktor lingkungan adalah faktor sosial, ekonomi dan perilaku masyarakat. Tujuan penelitian ini mengetahui faktor-faktor risiko lingkungan fisik (genangan air), lingkungan biologi (tanaman air, ikan predator), lingkungan sosial ekonomi (pekerjaan, pendidikan dan penghasilan) dan faktor perilaku (kebiasasaan keluar malam hari, kebiasaan menggunakan obat anti nyamuk dan kebiasaan menggunakan baju pelindung diri dari gigitan nyamuk) yang berpengaruh terhadap kejadian filariasis. Jenis penelitian ini merupakan penelitian observasional dengan rancangan studi kasus kontrol. Kasus adalah penduduk yang menderita filariasis dan kontrol adalah penduduk yang tidak menderita filariasis. Jumlah kasus dan kontrol adalah 80. Pengambilan data dilakukan melalui observasi dan wawancara. Analisis dilakukan secara bivariat dan multivariat dengan menggunakan regresi logistik. Analisis Multivariat menunjukkan bahwa dari 11 (sebelas) variabel yang dianalisis terdapat 1 variabel yang terbukti berpengaruh terhadap kejadian filariasis di Kecamatan Pekalongan Selatan, yaitu : Pemakaian Obat Anti Nyamuk $(\mathrm{OR}=35,286$, CI 95\% = 7,390 - 168,476). Penggunaan obat anti nyamuk merupakan faktor risiko yang paling dominan untuk terjadinya penularan filariasis. Masyarakat disarankan menggunakan kelambu atau anti nyamuk sewaktu tidur, memakai pelindung diri (baju dan celana panjang) waktu keluar rumah pada malam hari. Perlu adanya penyuluhan tentang filariasis dalam rangka meningkatkan pengetahuan masyarakat.
\end{abstract}

Kata kunci: filariasis, lingkungan, perilaku.

\section{VARIOUS ENVIRONMENTAL AND BEHAVIOR FACTORS THAT INFLUENCE THE FILARIASIS EVENT}

\begin{abstract}
Filariasis is a disease that is still a health problem in Indonesia. South Pekalongan District is one of the endemic areas of filariasis, it was found about 71 cases of filariasis. This is caused by many factors in the environment, such as swamp and pool that was flooded with water with many water plants. Other factor, that caused by are sosio economic and community behavior. The objective of this study was to determine physical factors (swamp / pool), Biological (water plants, fish / animal predators) of the environment. Socio ecomic factor (education, job and income), behaviour factor the habitat of (going outside at night, habit of using mosquito repellent and wearing clothes to protect from mosquitoes bite) that may give influence the filariasis cases in South Pekalongan District. This research was an observasional research with a case-control approach. Case in this study was filariasis cases and for control was people suffer from filariasis. Total sampler were 80 sample. Data was taken by observation and interview. Data collected was analyzed by using logistics regression. Multivariate analysis showed that from 11 variables, there are 1 variable were proved to be the risk factor of filariasis at South Pekalongan District, which are : respondent, habit of using mosquito repellent $(O R=35,286, C I 95 \%=7,390-168,476)$. The use of mosquito repellent is the most dominant risk factor for filariasis transmission. It is suggested that people sould use mosquito net or repellent when bed time, self protection dress when they go out at night. It is necessary to perform health promotion related to filariasis in order to improve people knowledge .
\end{abstract}

Keyword: Filariasis, Environmental, Behavioral. 


\section{PENDAHULUAN}

Filariasis disebabkan oleh infeksi parasit nematoda yang ditularkan oleh vektor filaria (Manson's, 2009). Tergantung pada spesiesnya, filaria dewasa dapat hidup di limfatik, pembuluh darah, kulit, jaringan ikat atau selaput serous. ${ }^{1}$ Sampai saat ini penyakit tersebut masih menjadi masalah kesehatan masyarakat di Indonesia, baik di daerah perkotaan maupun pedesaan. Pada tahun 2014 di Indonesia dilaporkan sebanyak 29 propinsi dan $239 \mathrm{Kab} / \mathrm{Kota}$ endemis filariasis, sehingga diperkirakan sebanyak 102,279,739 orang yang tinggal didaerah endemis tersebut yang berisiko terkena filariasis (Kemenkes, 2014).

Kota Pekalongan merupakan daerah yang banyak ditemukan kasus kronis filariasis. Berdasarkan laporan diketahui bahwa jumlah kasus filariasis yang ditemukan, dari dua belas kecamatan hanya satu kecamatan yang masih menjadi daerah endemis filariasis, yaitu kecamatan pekalongan selatan dari tahun 2014 - 2016 ditemukan ada 71 kasus (Dinkes Kota Pekalongan, 2016).

Upaya - upaya penanggulangan telah dilakukan terhadap penderita filariasis di Kota Pekalongan, antara lain dengan pengobatan penderita dengan menggunakan diethylcarbamazine (DEC) dosis 1 tablet per tahun selama 5 tahun, pengendalian vektor dengan fogging memakai insektisida organophospat dan sintetic pyretroid serta penyuluhan di setiap Posyandu oleh petugas Puskesmas terutama sebelum kegiatan pengobatan massal dilakukan. Namun kegiatan tersebut masih menemui beberapa kendala, antara lain belum diketahuinya tempat tempat perindukkan nyamuk serta berbagai faktor yang mendukung penyebaran filariasis di wilayah tersebut seperti faktor perilaku dimana sebagian masyarakat Kota Pekalongan biasa keluar rumah pada malam hari hanya untuk berkumpul makan diluar ataupun memang berkegiatan menjaga keamanan desa, mengikuti kegiatan pengajian, menjahit pada malam hari dan tidak semua masyarakat menggunakan pakaian yang melindungi dari gigitan nyamuk. Dalam penelitian ini penulis ingin meneliti berbagai faktor lingkungan dan perilaku yang berpengaruh terhadap kejadian filariasis (studi kasus daerah endemis di Kota Pekalongan) tahun $2014-2016$

\section{METODE}

Rancangan penelitian menggunakan Case Control Study, karena sesuai dengan tujuan penelitian yaitu menganalisis berbagai faktor lingkungan dan perilaku yang berpengaruh terhadap terjadinya suatu penyakit (Gordis, 2000). Besar sampel dari penelitian ini dihitung menggunakan rumus Stanley Lameshow (1997) diperoleh 40. Pengambilan sampel dilakukan dengan purposive sampling sesuai kebutuhan peneliti berdasarkan total populasi. Jumlah kasus dalam penelitian ini adalah 40 orang yang didapat dari data Dinas Kesehatan Kota Pekalongan. Tahun 2014 2016. Penelitian mengambil perbandingan antar kasus dan kontrol 1:1 maka jumlah kontrol adalah 40 orang. Jumlah sampel keseluruhan adalah 80 orang. Pelaksanaan kegiatan analisis data sekunder dilakukan dengan mengumpulkan data mengenai keadaan wilayah (meliputi topografi, batas - batas wilayah dan iklim; perumahan, meliputi jumlah rumah dan letak rumah); penduduk, (meliputi jumlah keluarga, nama kepala keluarga, jumlah anggota keluarga, pembagian penduduk menurut umur dan kelamin, serta jenis pekerjaan dan pendidikan).

Pengumpulan data dilakukan dengan wawancara terstruktur menggunakan kuesioner. Adapun kriteria inklusi penelitian yaitu, bersedia berpartisipasi dalam penelitian, tercatat sebagai penderita filariasis di Puskesmas dan Dinas Kesehatan, sudah berdomisili ditempat dimana ia tercatat sebagai sampel minimal selama tiga tahun, berdasarkan pemeriksaan mikroskopis pada sediaan darah jari dapat dinyatakan positif maupun negatif mikrofilaria.

Analisis deskriptif dilakukan untuk memberikan gambaran dan keadaan variabel penelitian Analisis bivariat dan multivariat untuk menguji hubungan antara faktor individu (jenis kelamin, umur dan pekerjaan), keadaan lingkungan sekitar pemukiman dan perilaku penduduk (sikap dan kebiasaan) penduduk terhadap penularan filariasis di Kelurahan Kuripan Kertoharjo dan Kelurahan Jenggot, Kecamatan Pekalongan Selatan, Kota Pekalongan. Analisis mempergunakan program SPSS, tingkat signifikansinya yaitu jika $\mathrm{p}=0,05$, maka terdapat hubungan yang signifikan Jika $\mathrm{p}>0,05$, maka tidak ada hubungan yang signifikan Penelitian ini mendapat kelaikan etik dari Komisi Etik 
Penelitian Kesehatan Fakultas Kedokteran Universitas Diponegoro dan RSUP dr. Kariadi Semarang.

\section{HASIL}

Hasil penelitian disajikan pada tabel berikut.

Tabel 1.

Karakteristik Responden Berdasarkan Umur $(n=80)$

\begin{tabular}{lcccccc}
\hline \multicolumn{1}{c}{$\begin{array}{c}\text { Kelompok umur } \\
\text { responden }\end{array}$} & \multicolumn{3}{c}{ Kelompok Responden } \\
& $\mathrm{f}$ & $\%$ & $\mathrm{f}$ & $\%$ & $\mathrm{f}$ & \multirow{2}{*}{ Kontrol } \\
\hline $12-16$ tahun & 0 & 0 & 2 & 5 & 2 & 2,5 \\
$17-25$ tahun & 9 & 22,5 & 5 & 12,5 & 14 & 17,5 \\
$26-35$ tahun & 5 & 12,5 & 13 & 32,5 & 18 & 22,5 \\
$36-45$ tahun & 13 & 32,5 & 15 & 37,5 & 28 & 35 \\
$46-55$ tahun & 9 & 22,5 & 4 & 10 & 13 & 16,3 \\
$56-65$ tahun & 3 & 7,5 & 1 & 2,5 & 4 & 5 \\
$>65$ tahun & 1 & 2,5 & 0 & 0 & 1 & 1,25 \\
\hline
\end{tabular}

Tabel 2.

Karakteristik Responden Kelompok Kasus dan Kontrol( $(n=80)$

\begin{tabular}{lcccc}
\hline \multicolumn{1}{c}{ Karakteristik } & \multicolumn{2}{c}{ Kasus } & \multicolumn{2}{c}{ Kontrol } \\
& $\mathrm{f}$ & $\%$ & $\mathrm{f}$ & $\%$ \\
\hline Jenis Kelamin & & & & \\
Laki-laki & 23 & 57,5 & 19 & 47,5 \\
Perempuan & 17 & 42,5 & 21 & 52,5 \\
Pendidikan & & & & \\
Tidak Sekolah & 6 & 15 & 0 & 0 \\
Tamat SD & 19 & 47,5 & 19 & 47,5 \\
Tamat SLTP & 9 & 22,5 & 13 & 32,5 \\
Tamat SLTA & 6 & 15 & 6 & 15 \\
Akademi/PT & 0 & 0 & 2 & 5 \\
Pekerjaan & & & & \\
Tidak Bekerja & 10 & 25 & 14 & 35 \\
PNS & 1 & 2,5 & 0 & 0 \\
Swasta & 1 & 2,5 & 0 & 0 \\
Petani & 1 & 2,5 & 0 & 0 \\
Buruh & 27 & 67,5 & 26 & 65 \\
Nelayan & 0 & 0 & 0 & 0 \\
\hline
\end{tabular}

Tabel 3.

Rekapitulasi Hasil Bivariat Variabel Faktor Risiko Kejadian Filariasis $(\mathrm{n}=80)$

\begin{tabular}{lccc}
\hline \multicolumn{1}{c}{ Variabel } & $P$ value & OR & $95 \%$ CI \\
\hline Jenis Pekerjaan Berisiko & 0,811 & 1,256 & $0,492-3,209$ \\
Tingkat Pendidikan Rendah & 0,261 & 1.842 & $0,755-4.493$ \\
Tingkat Penghasilan < UMR & 0,585 & 0,636 & $0,215-1,883$ \\
Adanya Keberadaan Kolam & 0,042 & 3,400 & $1,156-9,996$ \\
Adanya Keberadaan Rawa & 1,000 & 2,026 & $1,620-2,533$ \\
Adanya Tanaman Air & 0,615 & 3,162 & $0,315-31,775$ \\
Tidak Ada Ikan Pemakan Jentik & 0,769 & 0,706 & $0,221-2,259$ \\
Tidak Memakai Kelambu & 0,000 & 8,308 & $2,999-23,012$ \\
Tidak Memakai Obat Anti Nyamuk & 0,000 & 35,286 & $7,390-168,476$ \\
Sering Keluar Rumah Malam Hari & 0,003 & 4,500 & $1,731-11,696$ \\
Tidak Menggunakan Pakaian Panjang & 0,001 & 5,741 & $2,154-15,297$ \\
\hline
\end{tabular}


Tabel 4.

Hasil Analisis Variabel yang Mempunyai Hubungan Bermakna dengan Kejadian Filariasis $(\mathrm{n}=80)$

\begin{tabular}{lccc}
\hline \multicolumn{1}{c}{ Variabel } & $P$ value & OR & $95 \%$ CI \\
\hline Adanya Keberadaan Kolam & 0,042 & 3,400 & $1,156-9,996$ \\
Tidak Memakai Kelambu & 0,000 & 8,308 & $2,999-23,012$ \\
Tidak Memakai Obat Anti Nyamuk & 0,000 & 35,286 & $7,390-168,476$ \\
Sering Keluar rumah Malam Hari & 0,003 & 4,500 & $1,731-11,696$ \\
Tidak Menggunakan Pakaian Panjang & 0,001 & 5,741 & $2,154-15,297$ \\
\hline
\end{tabular}

Tabel 5.

Hasil Analisis Regresi Logistik Variabel Potensial dengan Kejadian Filariasis ( $\mathrm{n}=80$ )

\begin{tabular}{lccccc}
\hline \multicolumn{1}{c}{ Variabel } & $\beta$ & P value & OR & \multicolumn{2}{c}{$95,0 \%$ CIfor EXP $(\beta)$} \\
& & & & Lower & Upper \\
\hline Tidak Memakai Obat Anti Nyamuk & 3,563 & 0,000 & 35,286 & 7,390 & 168,476 \\
Constant & $-0,999$ & & & & \\
\hline
\end{tabular}

Tabel 3 menunjukkan kelima variabel memiliki $\mathrm{p}<0,05$, terdapat hubungan yang bermakna masing - masing antara adanya keberadaan kolam, penggunaan kelambu, pemakaian obat anti nyamuk, kebiasaan keluar rumah pada malam hari dan kebiasaan menggunakan pakaian panjang dengan kejadian filariasis di Kelurahan Kuripan Kertoharjo dan Kelurahan Jenggot, Kecamatan Pekalongan Selatan, Kota Pekalongan.

Tabel 4 menunjukkan bahwa kelima variabel potensial sebagai faktor risiko kejadian filariasis diatas, selanjutnya dilakukan analisis secara multivariat menggunakan regresi logistik. Karena pada penelitian ini menggunakan desain case control, maka dalam analisis regresi logistik digunakan metode backward conditional.

\section{PEMBAHASAN}

Kecamatan Pekalongan Selatan memiliki 5 wilayah administrasi Kelurahan yaitu Kelurahan Jenggot, Kelurahan Banyurip, Kelurahan Buaran Kradenan, Kelurahan Kuripan Kertoharjo, Kelurahan Yosorejo, Kelurahan Soko Duwet. Secara Geografis terletak di :109. - 110 Bujur Timur, 6 - 7 Lintang Selatan, beriklim tropis Type A dengan variasi hujan antara 46 hingga $487 \mathrm{~mm}$ tiap bulan dengan curah hujan terendah pada bulan Juni (BPS Kota Pekalongan, 2017).

Kecamatan Pekalongan Selatan memiliki luas daerah lebih kurang 10,08 $\mathrm{Km}^{2}$, secara geografis terletak di bagian Selatan Kota Pekalongan dengan batas wilayah sebagai berikut: Sebelah Utara : Kec. Pekalongan Barat dan Kec. Pekalongan Timur, Sebelah Timur :
Kabupaten Batang, Sebelah Selatan : Kabupaten Pekalongan, Sebelah Barat : Kec. Pekalongan Barat, Kelurahan Kuripan Kertoharjo dan Kelurahan Jenggot merupakan kelurahan yang dipilih sebagai subyek penelitian karena berdasarkan hasil survei pendahuluan ditemukan kasus filariasis selama tiga tahun berturut - turut pada tahun 2014 2016.

Berdasarkan pengamatan di lapangan didapatkan pada kelompok kasus umur 12-16 tahun tidak ada responden, kelompok umur 1725 tahun sebanyak 9 responden (22,5\%), kelompok umur 26-35 tahun sebanyak 5 responden (12,5\%), kelompok umur 36-45 tahun sebanyak 13 responden $(32,5 \%)$, pada kelompok umur 46 - 55 tahun sebanyak 9 responden ( $22,5 \%$ ), pada kelompok umur 56 65 tahun sebanyak 3 responden $(7,5 \%)$ dan pada kelompok umur > 65 tahun sebanyak 1 responden $(2,5 \%)$. Sedangkan pada kelompok kontrol umur 12-16 tahun 2 responden, $(5,0 \%)$, kelompok umur 17-25 tahun sebanyak 5 responden (12,5\%), kelompok umur 26-35 tahun sebanyak 13 responden $(32,5 \%)$, kelompok umur 36-45 tahun sebanyak 15 responden $(37,5 \%)$, pada kelompok umur 46 55 tahun sebanyak 4 responden $(10,0 \%)$, pada kelompok umur 56 - 65 tahun sebanyak 1 responden $(2,5 \%)$ dan tidak terdapat responden pada kelompok umur $>65$ tahun.

Berdasarkan hasil analisis dengan regresi logistik (terhadap lima variabel potensial), seperti tampak pada tabel 5. ternyata hanya satu variabel yang menjadi faktor risiko kejadian filariasis di Kecamatan Pekalongan Selatan, yaitu pemakaian obat anti nyamuk 
responden dengan koefisien regresi : 3,563. Dengan demikian faktor risiko tersebut bisa digunakan untuk merumuskan model persamaan regresi logistik sebagai berikut :

$$
\begin{aligned}
y & =-0,999+(3,563) \\
& =2,564 \\
P & =\frac{1}{1+2, / 18^{-(-y)}} \times 100 \\
P & =\frac{1}{1+2,118^{-(-2,564)}} \times 100 \\
P & =\frac{1}{1+12,984} \times 100 \\
P & =\frac{1}{13,484} \times 100 \\
= & 0,0 / 2 \times 100 \\
& =7,151 \%
\end{aligned}
$$

Dengan demikian, bila seseorang tidak menggunakan obat anti nyamuk pada saat sebelum tidur, maka mempunyai probabilitas menderita filariasis sebesar $7,151 \%$.

Pemakaian obat anti nyamuk memiliki hubungan yang signifikan dan merupakan salah satu faktor determinan yang berpengaruh terhadap kejadian filariasis di wilayah Kecamatan Pekalongan Selatan. Hasil penelitian ini sejalan dengan penelitian Garjinto (2013) dan Syuhada (2012) yang dapat membuktikan bahwa tidak menggunakan obat anti nyamuk pada malam hari merupakan perilaku berisiko terhadap kejadian filariasis. Meskipun berhubungan secara bermakna dengan kejadian filariasis, keempat variabel selain pemakaian obat anti nyamuk tidak berkontribusi secara bermakna dalam analisis regresi logistik. Beberapa hal yang mungkin menyebabkan hal tersebut adalah keterbatasan jumlah sampel untuk analisis regresi logistik dan kemampuan kuesioner penelitian menterjemahkan variabel adanya keberadaan kolam, tidak memakai kelambu, sering keluar rumah malam hari dan tidak menggunakan pakaian panjang.

\section{SIMPULAN DAN SARAN Simpulan}

Hasil penelitian menunjukkan faktor yang berhubungan secara bermakna dengan kejadian filariasis adalah pemakaian obat anti nyamuk, sedangkan Adanya keberadaan kolam, tidak memakai kelambu, sering keluar rumah malam hari dan tidak menggunakan pakaian panjang ditemukan hanya berhubungan pada analisis bivariat. Hal ini dimungkinkan karena masih terdapat banyak faktor yang berinteraksi mempengaruhi kejadian filariasis di wilayah Pekalongan Selatan.

\section{Saran}

Pihak Dinas Kesehatan perlu untuk membuat inovasi - inovasi tentang pencegahan filariasis selain dengan cara pengobatan massal, seperti pembagian kelambu berinsektisida dan pembagian bubuk larvasida. Pihak Puskesmas Kuripan Kertoharjo dan Puskesmas Jenggot perlu melakukan penyuluhan secara teratur tentang filariasis guna meningkatkan pengetahuan masyarakat.

Masyarakat disarankan menggunakan kelambu atau obat anti nyamuk sewaktu tidur, memakai pelindung diri (baju dan celana panjang) waktu keluar rumah pada malam, meminimalkan adanya tanaman air, guna mengurangi breeding place dan resting place dengan menggalakkan kegiatan Jum'at bersih.

\section{DAFTAR PUSTAKA}

Manson's. (2009. Tropical Diseases. Editor : Gordon c. Cook \& Alimuddin I. Zumla, Saunders Elsevier, Twenty-second edition, China, 2009; 1477

Pusat Data dan Surveilans Epidemiologi (2014). Kementerian Kesehatan RI. Filariasis di Indonesia.

Dinas Kesehatan Kota Pekalongan. (2016). Profil Din Kes Kota Pekalongan.

Dinas Kesehatan Kota Pekalongan. (2016). Laporan Tahunan Dinkes Kota Pekalongan.

Gordis L. (2000). Case Control and Cross Sectional Studies in Epidemiologi, $2^{\text {nd }}$ ed. Philadelpia, W.B. Saunders Company; 2000:140-156.

Anggraeni, D.M \& Saryono. (2013). Metodologi Penelitian Kualitatif dan Kuantitatif dalam Bidang Kesehatan. Yogyakarta: Nuha Medika, 2013; 85

Lameshow S, Hosmers J, Klar J, Lwanga S.K. (1997). Besar Sampel dalam Penelitian Kesehatan, diterjemahkan oleh 
Pramono. Yogyakarta: Gadjah Mada University Press.

BPS Kota Pekalongan. (2017). Profil Kota Pekalongan.

Garjit0. (2013). Triwibowo. Filariasis dan Beberapa Faktor yang Berhubungan dengan Penularannya di Desa PangkuTolole, Kecamatan Ampibabo, Kabupaten Parigi - Moutong, Provinsi Sulawesi Tengah. Jurnal Vektora Volume V No.2, 2013

Syuhada, Yudi. (2012). Studi Kondisi Lingkungan Rumah dan Perilaku Masyarakat sebagai Faktor Risiko Kejadian Filariasis di Kecamatan Buaran dan Tirto Kabupaten Pekalongan. Jurnal Kesehatan Lingkungan Indonesia. Volume 11 No. 1,2012 